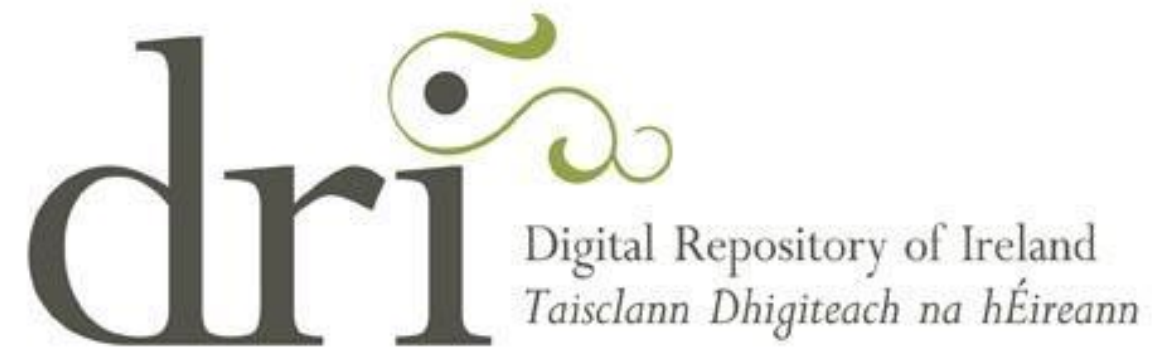

\title{
THE DIGITAL REPOSITORY OF IRELAND: REQUIREMENTS SPECIFICATION
}

\section{AUTHORS:}

Dr. Sharon Webb, Knowledge Transfer Manager, Royal IRISH Academy (Former ReQuirementS ANALYST)

Charlene McGoohan, ReQuirements Manager, Maynooth University

When citing this document, please use the following wording: Webb, S. and McGoohan, C. (2015), Digital Repository of Ireland: Requirements. National University of Ireland Maynooth. DOI: http://dx.doi.org/10.3318/DRI.2015.6 


\section{INTRODUCTION}

The Digital Repository of Ireland (DRI) is a national trusted digital repository for Ireland's social and cultural data. The repository links together and preserves both historical and contemporary data held by Irish institutions, providing a central internet access point and interactive multimedia tools. As a national e-infrastructure for the future of education and research in the humanities and social sciences, DRI is available for use by the public, students and scholars. DRI also acts as a focal point for the development of national guidelines and policy for digital preservation and access.

"The successful implementation of DRI's fundamental aim, to build an interactive trusted digital repository (TDR), is dependent upon the system's ability to implement its stated requirements and satisfy identified user needs. From the outset DRI committed to developing a system that reflects the authentic needs of its designated and diverse community of users."

(Cassidy et al., 2015)

The requirements analysis efforts of the DRI were initially informed by the findings from interviews conducted with forty Irish institutions concerned with humanities and social science data. These interviews were particularly focused on the institutions' activities and needs regarding types of digital digital data; sharing and reuse; preservation; storage and formats; metadata and interoperability; user tools; and structuring content. The outcomes of these interviews can be examined more closely in 'Digital Archiving in Ireland: National Survey of the Humanities and Social Sciences' (O'Carroll \& Webb, 2012).

This document details the current specified requirements of the DRI, at time of publication. Please note that requirements engineering is an iterative process, hence, throughout the course of development of the Repository some requirements have been replaced, edited, or become obsolete. Therefore, inconsistencies in the numbering of the requirements and/or sub requirements may occur. In addition, the DRI is currently an ongoing project, ergo not all requirements have been fully implemented to date.

The requirements of the DRI were actively managed throughout the development of the Repository, a history of all changes made are included in internal documentation within the DRI. The requirements are also categorised according to where the requirement may have come from, which aided the management of the requirements throughout the duration of the project thus far, these categories have been included in this document. The specified requirements within this document are requirements statements and specifications, thus do not include any implementation choices in the development of the system. 


\section{REQ-1 A TRUSTEd DigitAl REPOSITORY}

\section{BUSINESS REQUIREMENT}

The system shall be a trusted digital repository.

1.1 It shall supply provide 'reliable, long-term access to managed digital resources to its designated community, now and in the future'.

1.2 It shall conform to the Data Seal of Approval guidelines or equivalent.

1.3 It shall be an access repository for the humanities and social sciences (HSS).

1.4 It shall have disaster recovery process in place. (REQ-57)

\section{REQ-2 AN INTERACTIVE TDR WITH RESEARCH TOOLS}

\section{BUSINESS REQUIREMENT}

The system shall be an interactive trusted digital repository.

1.1 It shall provide multimedia tools to research and interact with archived data.

1.2 It shall provide analytical and visualisation tools.

1.3 It shall provide tools for the innovative analysis of data.

1.4 It shall provide tools for innovative secondary, longitudinal and comparative analysis of data.

1.5 It shall provide a suite of research tools for data that share formats and conventions.

\section{REQ-3 INTERFACE WITH EU RESEARCH INFRASTRUCTURE}

\section{BUSINESS REQUIREMENT}

The system shall interface with similar developing EU research infrastructures.

\section{REQ-4 A ROBUST TDR}

\section{NON-FUNCTIONAL REQUIREMENT}

The system shall be robust.

1.1 It shall handle unexpected system errors.

1.2 It shall not terminate in case of invalid requests.

1.3 It shall not terminate in case of unexpected flood of requests.

1.4 It shall handle $X$ concurrent users without any degradation of service or response time.

\section{REQ-5 A SCALABLE TDR}

\section{NON-FUNCTIONAL REQUIREMENT}

The system must be able to increase performance when new resources are added. 
1.1 It shall increase performance when new hardware/storage is added.

1.2 It shall 'handle anticipated future volumes of both bytes and files without a major disruption to the system'.

1.3 It shall 'be designed to accommodate future formats (media and files) without major disruption to the system'.

1.4 It shall be extensible (e.g. add new technologies).

\section{REQ-6 AN ACCESSIBLE TDR}

NON-FUNCTIONAL REQUIREMENT

The system must follow best practices and standards for web accessibility.

1.1 It shall adopt HTML5/WAI-ARIA guidelines to maximize assistive technology support.

\section{REQ-7 A SUSTAINABLE TDR}

NON-FUnCTIONAL REQUIREMENT

The system shall be sustainable.

1.1 It shall be developed under an open source license.

\section{REQ-7.1 SUPPORT A SUBSCRIPTION MODEL}

\section{BUSINESS REQUIREMENT}

The system may support a subscription model.

\section{REQ-8 Support COMmon DatA ANd Metadata Formats AND StandardS}

\section{BUSINESS REQUIREMENT}

The system shall support common data and metadata formats and standards.

1.1 It shall support common data formats as decided by policy.

1.2 It shall support a wide variety of multimedia resources.

1.3 It shall support common metadata standards as decided by policy.

\section{REQ-8.1 RELATIONSHIPS}

\section{FUNCTIONAL REQUIREMENT}

The system shall support relationships between digital objects. 


\section{REQ-9 IMPLEMENT ACCESS RIGHTS}

\section{FUNCTIONAL REQUIREMENT}

The system shall manage access to digital objects through authentication and authorization mechanisms.

1.1 It shall manage access rights for different levels of users (e.g. Anonymous User, Registered User, Authorised User)

1.2 It shall manage access rights for digital objects and collections.

1.3 It shall provide security to digital objects by mapping access rights between digital objects and users.

1.4 A digital object shall not be placed in breach of access rights (consent) e.g. It shall deny access to Un-trusted user.

\section{REQ-9.1 GRANT ACCESS RIGHTS}

\section{FUnCTIONAL REQUIREMENT}

The system must allow an authorised user to grant a user access rights to a digital object or to a collection.

\section{REQ-9.2 EDIT ACCESS RIGHTS}

\section{FUNCTIONAL REQUIREMENT}

The system must allow an authorised user to edit (e.g. revoke) access rights to a user, a group, a digital object or a collection.

\section{REQ-10 Common Portal to Institutional Repositories And Digital ARCHIVES}

\section{BUSINESS REQUIREMENT}

The system shall provide a common portal for discovery and access to a range of institutional repositories and digital archives

1.1 It shall be a portal to other partnered repositories and digital archives.

1.2 It shall interface with other partnered repositories and digital archives.

\section{REQ-11 Multi-MOdal RENDERING TeCHnOLOGY}

\section{FUNCTIONAL REQUIREMENT}

The system must support multi-modal rendering technologies.

1.1 It shall support all standard HTML 5 media types. 


\section{REQ-12 REST BASED API}

\section{FUNCTIONAL REQUIREMENT}

The system must support user client development through a REST based API.

1.1 It may allow an Expert User to reuse and repurpose data, in accordance with their access rights and the rights of the digital object, through the API.

\section{REQ-13 INTERFACE PROFILES}

\section{INTERFACE REQUIREMENT}

The system shall implement responsive and adaptive web design.

1.1 It shall be responsive when used on different devices e.g. mobile, tablet, desktop monitor.

1.2 It shall be adaptive to device capabilities.

1.3 It shall gracefully degrade on mobile devices.

\section{REQ-15 SUPPORT A BILINGUAL (GAEILGE/ENGLISH) INTERFACE}

\section{FUNCTIONAL REQUIREMENT}

The system must provide bilingual (Gaeilge/English) static interface elements where appropriate.

1.1 It must allow a user to toggle between Gaelige/English versions of the UI.

\section{REQ-16 METADATA EXPORT}

\section{FUnCTIONAL REQUIREMENT}

The system shall export metadata in the format it was originally ingested.

\section{REQ-17 INGEST DIGITAL OBJECTS}

\section{FUNCTIONAL REQUIREMENT}

The system must allow the user to ingest digital objects into a collection in accordance with their access rights.

1.1 It must check for duplicate digital objects on a collection basis (e.g. check metadata)

1.2 It must check, validate and verify the digital object (REQ-17.4).

1.3 It must allow the user, in accordance with their access rights, to specify the target collection for ingested digital objects.

1.4 It must allow the user, in accordance with their access rights, to specify the license for the ingested digital objects.

1.5 It must reject a digital object if it does not pass the malware scan.

1.6 It must not publish a digital object until the access controls are specified. 
Digital Repository of Ireland: Requirements

1.7 It must create an ingest report, for each ingested collection, available to authorised users only. (REQ-17.5)

\section{REQ-17.1 XML VALIDATION}

\section{FUnCTIONAL REQUIREMENT}

The system shall carry out validation of metadata (XML) against relevant metadata schema.

1.1 It must notify the user of any errors in the XML (a fail scenario).

\section{REQ-17.3 MALWARE SCAN (AT INGEST)}

\section{FUNCTIONAL REQUIREMENT}

The system must carry out a malware scan on all digital objects at point of ingestion.

1.1 It must reject and not ingest any infected digital objects.

1.2 It must notify the user of results of the malware diagnosis.

\section{REQ-17.4 CHECKSUM}

\section{FUNCTIONAL REQUIREMENT}

The system must create and record a checksum for all digital objects at point of ingestion.

\section{REQ-17.5 INGEST REPORT}

\section{FUNCTIONAL REQUIREMENT}

The system must automatically generate a report following the ingest process.

1.1 The report must list digital objects that were ingested successfully.

1.2 The report must list digital objects that were not ingested.

1.2.1 It must outline the reasons why a digital object failed the ingest process e.g. insufficient metadata fields.

\section{REQ-17.6 SINGLE INGEST}

\section{FUnCTIONAL REQUIREMENT}

The system must allow a user, in accordance with their access rights, to ingest a single digital object through a web form. 


\section{REQ-17.7 BULK INGEST}

\section{FUNCTIONAL REQUIREMENT}

The system must allow a user, in accordance with their access rights, to bulk ingest digital objects (DO plus associated metadata) into the repository, in accordance with their access rights, through semiautomated means.

1.1 It must allow a user, in accordance with their access rights, to bulk ingest through a command line app.

1.2 It must allow a user, in accordance with their access rights, to bulk ingest through a web interface.

\section{REQ-18 MetadATA MaPpING}

\section{FUNCTIONAL REQUIREMENT}

The system may provide metadata mapping tools.

\section{REQ-19 CROSS SEARCH FunctionALITY}

\section{FUNCTIONAL REQUIREMENT}

The system must support cross search functionality.

1.1 It must search all internal DRI collections and external collections in accordance with the access rights of the user and the collections.

1.2 It must aggregate metadata from DRI and DRI partner institutions in accordance with the access rights of the user and the collections.

\section{REQ-20 SEARCH CRITERIA}

\section{FUNCTIONAL REQUIREMENT}

The system must allow a user to carry out a simple search query using free text keywords.

1.1 It must allow the user to include Boolean commands (e.g. "AND", "OR") in the free text query.

1.2 It must allow the user to carry out phrased searching.

1.3 It must allow the user to carry out a full-text search query (e.g. all text in a document or database) and a search query based on metadata only.

1.4 It may autocomplete the user's free text query.

1.5 It may alert the user to typing errors or misspelled keywords. 


\section{REQ-20.2 REFINE SEARCH RESULTS (FACET)}

\section{FUNCTIONAL REQUIREMENT}

The system must allow the user to refine their search criteria through a faceted search bar.

1.1 It must allow the user to filter the search through faceted navigation based on metadata fields as indicated by policy.

1.2 It must allow the user to filter the search through faceted navigation based on the collections accessible by the user.

1.3 It may dynamically change the faceted navigation metadata fields in response to the user's selection of particular data types (e.g. audio data and 'broadcast date').

\section{REQ-20.3 FUZZY STRING MATCHING}

\section{FUNCTIONAL REQUIREMENT}

The system must carry out fuzzy string matching on the user's search query.

\section{REQ-21 Generate Surrogate Digital ObJects}

\section{FUNCTIONAL REQUIREMENT}

The system shall generate surrogate formats from primary digital object as required.

1.1 It shall display derived assets (digital objects) as required (e.g. high resolution TIFF to low resolution thumbnail in JPEG).

\section{REQ-22 USER WORKSPACES}

\section{FunCTIONAL REQUIREMENT}

The system must support the creation of user workspaces

1.1 It shall allow the user to bookmark their search query, in accordance with their access rights.

1.2 It shall allow the user to bookmark their search results, in accordance with their access rights.

1.3 It shall allow the user to bookmark an edited collection of search results, in accordance with their access rights.

1.4 It shall allow the user to create a dossier to bookmark digital objects, in accordance with their access rights.

1.5 It shall allow the user to remove bookmarked digital objects from their dossier, in accordance with their access rights.

1.6 It may allow users to share their personal dossier with other users, in accordance with the access rights of the user and the digital object. 


\section{REQ-22.1 CURATEd COLLECTIONS}

\section{FUNCTIONAL REQUIREMENT}

The system may support the creation of a user created (curated) collection in a user's workspace (e.g. collating digital objects from different collections, online exhibitions).

1.1 It may allow users to share a curated collection with other users in accordance with the access rights of the user and the digital objects.

\section{REQ-22.2 USER PROFILES}

\section{FUNCTIONAL REQUIREMENT}

The system shall support the creation of user profiles.

\section{REQ-23 CREATE USER ACCOUNTS}

\section{FUNCTIONAL REQUIREMENT}

The system must allow anonymous users to create a username and password.

1.2 It shall alert the Anonymous User of a conflicting email.

1.3 It shall email the Anonymous User an confirmation link.

\section{REQ-25 HaRVEST AND/OR Aggregate Digital OBJECTS}

\section{FUNCTIONAL REQUIREMENT}

The system must harvest and/or aggregate digital objects from external repositories (or DRI partners) and allow third parties to harvest from DRI according to the access rights of the digital objects.

1.1 It shall update metadata from external repositories at regular intervals (to be defined).

\section{REQ-26 RETRIEVE SEARCH RESULtS}

\section{FUNCTIONAL REQUIREMENT}

The system shall retrieve a list of digital objects based on the search criteria/query and the user and the digital objects access policies.

1.1 It shall return digital objects that match the user access rights.

1.2 It shall return metadata that match the user access rights.

1.3 It shall not return any restricted digital objects or metadata to unauthorized users. 


\section{REQ-26.1 Display SEARCH RESULTS}

\section{FUNCTIONAL REQUIREMENT}

The system must display all search results related to a user's search query.

1.1 It must display the search results in an ordered list by default.

1.2 It may display search results through a visualization as specified by the user (e.g. map or timeline).

1.3 It must display metadata fields as indicated by policy.

1.4 It may rank search results of topical relevance.

1.5 It must allow the user to filter search results based on metadata fields as indicated by policy.

\section{REQ-26.1.1 DISPLAY THUMBNAILS}

\section{FunCTIONAL REQUIREMENT}

The system must include a thumbnail of digital objects, in accordance with access rights, where available in the search results.

\section{REQ-26.1.2 DISPLAY SNIPPET VIEW}

\section{FUNCTIONAL REQUIREMENT}

The system may display a snippet view of text related to a search item (e.g. paragraph from an article), in accordance with access rights.

1.1 It may highlight the search query within the snippet.

\section{REQ-26.1.3 SUGGESTED ITEMS}

\section{FunCTIONAL REQUIREMENT}

The system may alert the user to suggested digital objects based on a selected item.

\section{REQ-26.1.4 HYPER-LINKED METADATA FIELDS}

\section{FUNCTIONAL REQUIREMENT}

In views of the digital object the system must display metadata fields as hyperlinks if they have been indexed as facetable.

1.1 Each hyperlink must load a new search derived from the indexed facet of the metadata field value. 


\section{REQ-26.1.5 MAPPING INTERFACE SEARCH RESULTS}

\section{FUNCTIONAL REQUIREMENT}

The system must provide geocoded latitude and longitude and text labels for search results for use in mapping visualizations.

1.1 It must provide the north, east, west and southerly limits to display bounded boxes (or regions).

\section{REQ-26.1.6 TIMELINE INTERFACE SEARCH RESULTS}

\section{FunCTIONAL REQUIREMENT}

The system must accept formatted dates for use in timeline visualizations.

\section{REQ-27 IRISH LANGUAGE METADATA}

\section{FunCTIONAL REQUIREMENT}

The system must allow the user to distinguish between Irish and English language metadata where translations exist.

\section{REQ-28 DePositor TeMPLATEs/BRANDING}

\section{FUNCTIONAL REQUIREMENT}

The system may allow depositors to brand their digital objects and collections.

1.1 It may allow depositors to upload a collection logo.

1.2 It may allow depositors to save their 'institutional/company' profile.

\section{REQ-30 DATA CITATION}

\section{FUnCTIONAL REQUIREMENT}

The system must enable a user to export a citation.

1.2 It shall allow the user to export a digital object citation.

1.3 It shall allow the user to export a collection citation.

1.4 It shall export the details of the content owner in a citation.

1.5 It shall allow the user to export a citation in a range of formats.

1.6 It may allow the user to export a URL to a data visualization.

1.7 It may use a data citation format developed by DRI.

1.8 It may export citations to a citation management system. 


\section{REQ-30.2 Global PID (Persistent Identifier)}

\section{FUNCTIONAL REQUIREMENT}

The system must allocate a global PID to digital objects.

1.1 It must adhere to the rules set out by the global PID provider.

\section{REQ-31 USER COMMENTS (USER GENERATED CONTENT)}

\section{FUNCTIONAL REQUIREMENT}

The system may support user comments on digital objects in accordance with user access policy and the digital object's access policy.

\section{REQ-32 Copyright And End-user Statements/Agreements}

\section{LEGAL REQUIREMENT}

The system must map copyright statements and reuse licence to digital objects.

1.1 It must display copyright statements to end users.

1.2 It must display reuse licence (terms and conditions) to end users (e.g. Anonymous User, Registered User).

\section{REQ-33 SOCIAL MEDIA}

\section{FUNCTIONAL REQUIREMENT}

The system must support the use of social media.

1.1 It shall display social media 'follow' buttons (e.g. follow us on Twitter) on main website (CMS).

1.2 It may display social media sharing buttons for open content only.

1.2.1 It may allow users to share (a link) to a digital object on social media sites in accordance with access rights.

\section{REQ-34 Data PRESERVATION}

\section{BUSINESS REQUIREMENT}

The system must 'identify and manage the risks to its preservation operations and goals associated with the system infrastructure'.

1.1 It must 'employ technology watches or other technology monitoring notification systems'.

1.2 It must 'have procedures in place to monitor and receive notifications when hardware changes are needed'.

1.3 It must 'have procedures in place to monitor and receive notifications when software 
Digital Repository of Ireland: Requirements

changes are needed'.

1.4 It must allow a user, in accordance with their access rights, to migrate from one format to another in response to changes or obsolescence in software or media. (REQ-21)

\section{REQ-37 DOWNLOAD FILES}

\section{FUNCTIONAL REQUIREMENT}

The system shall allow users to download files to their local drive in accordance with their access rights and the object's access rights.

1.1 It shall allow the user to download files and data using user selected formats provided by DRI.

1.2 It may alert the user to any copyright and reuse restrictions.

1.3 It may display to the user a user license agreement.

\section{REQ-38 INGEST MULTIPLE DATA TYPES}

\section{BUSINESS REQUIREMENT}

The system shall enable the user to upload multiple data types into a collection in accordance with their access rights.

\section{REQ-41 OPERATE ON STANDARD INTERNET BROWSERS}

\section{FUNCTIONAL REQUIREMENT}

The system shall operate through standard compliant browsers.

\section{REQ-42 EDIT A DIGITAL OBJECT}

\section{FUNCTIONAL REQUIREMENT}

The system shall enable a user to edit digital objects in a collection in accordance with their access rights.

1.1 It shall implement version control of digital objects.

1.2 The user may only soft delete digital objects in accordance with their access rights.

1.3 The user shall have access to a digital object's version history in accordance with their access rights.

1.4 It must update and notify the Global PID system of changes based on their policy. 


\section{REQ-43 EDIT A COLLECTION}

\section{FUNCTIONAL REQUIREMENT}

The system must enable a user to edit a collection in accordance with their access rights.

1.1 It shall allow the user to add digital objects to a collection.

1.2 It shall allow the user to soft delete digital objects in a collection.

1.3 It shall allow the user to soft delete a collection, in part or whole.

1.4 It shall allow the user to modify the collection name and description.

1.5 It shall allow the user to modify the collections access rights (e.g. private, public or restricted).

1.6 It shall manage version control of digital objects replaced/edited in a collection.

\section{REQ-43.1 PubLISH A COLLECTION}

\section{FunCTIONAL REQUIREMENT}

The system must allow an authorised user to publish a collection in accordance with their access rights.

\section{REQ-43.1.1 EMBARGO NOTIFICATION}

\section{FUNCTIONAL REQUIREMENT}

The system must notify the collection manager in advance that a digital object or a collection is due for publication after a specific embargo date has passed.

\section{REQ-43.2 UN-PUBLISH A COLLECTION}

\section{FUNCTIONAL REQUIREMENT}

The system must allow an Authorised User to un-publish (remove access or hide) a collection in accordance with their access rights.

1.1 It must allow an authorised user to request the deletion of a collection.

\section{REQ-44 Reporting AND USAge ANALYTICS (CM)}

\section{FUNCTIONAL REQUIREMENT}

The system must allow users to review and download usage reports of content relative to their access rights.

1.1 It must allow a collection manager to review usage reports of their collections with respect to current legislation. 
Digital Repository of Ireland: Requirements

\section{REQ-44.1 Reporting AND USAge AnAlytics (SA)}

\section{FUNCTIONAL REQUIREMENT}

The system must allow users to review and download usage reports of content relative to their access rights.

1.1 It must allow a system administrator to review usage report of the system with respect to current legislation.

\section{REQ-46 SECURE}

\section{SECURITY REQUIREMENT}

The system shall be secure

1.1 It shall have procedures in place to reduce the risk of security incidents.

1.2 It shall be designed to follow industry standards and best practices regarding security procedures.

1.3 It shall be designed to enable security updates to software according to policy.

\section{REQ-46.1 INTRUSION DETECTION}

\section{SECURITY REQUIREMENT}

The system must 'detect and record all attempted accesses that fail identification, authentication and authorization requirements'.

1.1 It shall notify DRI System Administrator (or data security centre) of 'all failed attempted accesses during the previous 24 hours'

1.2 It shall notify DRI System Administrator (or data security centre) of any 'repeated failed attempts to access' databases.

\section{REQ-47 FEDERATEd STORAGE}

\section{FUNCTIONAL REQUIREMENT}

The system will use federated storage that will contain a collection of autonomous storage resources connected via a network and governed by one common management system that incorporates rules about how the federated data will be stored, managed, migrated.

\section{REQ-48 USER SUPPORT (WIKI/HELP)}

\section{FUNCTIONAL REQUIREMENT}

The system must provide the users with various access points to help resources.

1.1 It must provide a help page (or wiki) with multiple topic guides as indicated by policy. 
1.2 It may provide online video tutorials on multiple topics as indicated by policy.

1.3 It may provide context sensitive tooltips.

1.4 It may provide interactive 'tour guides'.

\section{REQ-49 SUBSCRIBE TO A COLLECTION}

\section{FUNCTIONAL REQUIREMENT}

The system may allow users to subscribe to a collection.

1.1 It may inform the user of collection updates.

1.2 It may allow the authorised user to send notifications to subscribed users.

\section{REQ-50 CURRENT LEGISLATION}

\section{NON-FUNCTIONAL REQUIREMENT}

The system must adhere to current legislation.

1.1 It must adhere to current copyright law.

1.2 It must adhere to current data protection legislation.

1.3 It must adhere to current freedom of information legislation.

1.4 It may adhere to the current Archives Act.

1.5 It may adhere to current CSO legislation.

\section{REQ-50.1 DisPLAY TERMS AND CONDITIONS AND LICENSE}

\section{FUNCTIONAL REQUIREMENT}

The system must display a terms and conditions of use to an anonymous user.

\section{REQ-51 SINGLE SIGN-ON/AUTHORISATION}

\section{FUnCTIONAL REQUIREMENT}

The system may support multiple third party authorisation mechanisms.

\section{REQ-52 A MULTI-LINGUAL INTERFACE}

\section{FUNCTIONAL REQUIREMENT}

The system may support a multi-lingual interface. 


\section{REQ-55 FOI REQUEST}

\section{LEGAL REQUIREMENT}

The system must support a Freedom of Information request

1.1 It must provide a user with access to all their personal account information held by the system.

1.2 It must prevent unauthorised users from gaining access to personal account information.

\section{REQ-57 DISASTER RECOVERY}

\section{BUSINESS REQUIREMENT}

The system must have disaster recovery procedures in place to ensure that any digital objects that are lost or corrupt through hardware or software failure can be restored to its last known good configuration.

\section{REQ-58 Delete a Collection}

\section{FUNCTIONAL REQUIREMENT}

The system must allow a System Administrator, with authorisation from DRI management, to delete a collection from the repository, following an approved request from an Authorised User or a legal entity.

1.1 The collection must be deleted from the repository and all back-ups.

\section{REQ-60 DATA INTEGRITY}

\section{FunCTIONAL REQUIREMENT}

The system must check the integrity of all communications and data held in the repository.

1.1 It must provide the user with mechanisms to check the integrity of digital objects at delivery and access point.

1.2 It must prevent corruption of all data held in the repository.

\section{REQ-61 CREATE a Collection}

\section{FUNCTIONAL REQUIREMENT}

The system must allow a user, in accordance with their access rights, to create a new collection. 1.1 It must alert the user to the deposit agreement terms and conditions and may allow them to upload a new deposit agreement.

1.2 It must allow a user, in accordance with their access rights, to submit collection level metadata. 
1.3 It must allow a user, in accordance with their access rights, specify the access controls, permission and licenses of the collection.

1.4 It must allow a user to save a collection in a draft state.

1.5 It must allow a user to submit a collection for publication.

1.6 It must ask the user to review the collections metadata, license and access rights before the collection is published.

\section{REQ-61.1 CREATE A SUb-COlLECTION}

\section{FUNCTIONAL REQUIREMENT}

The system must allow a user, in accordance with their access rights, to create sub-collections in a collection.

\section{REQ-62 AUDIT TRAIL}

\section{FUNCTIONAL REQUIREMENT}

The system must manage and save all information related to internal user and external user and system interaction with the repository in accordance with current legislation.

1.1 It must track all changes made to a digital object.

1.2 It must track all changes made to a collection.

1.3 It must track all changes made to user access permissions.

1.4 It may track all user login and log outs.

1.5 It must track all virus scans and integrity checks that are carried out by the system, including intermittent system checks as well as at point of ingestion.

\section{REQ-62.1 AUDIT REPORT}

\section{FUNCTIONAL REQUIREMENT}

The system must generate and make available to a user, according to their access rights, a custom generated audit report of user interactions with the system.

1.1 It must allow a user, in accordance with their access rights, to create an audit report for the full repository.

1.2 It must allow a user, in accordance with their access rights, to create an audit report for a collection they have access to.

\section{REQ-63 BRoWse by Collection}

\section{FUNCTIONAL REQUIREMENT}

The system must allow a user to browse collections in accordance with their access rights. 


\section{REQ-64 MALWARE SCAN}

\section{FUNCTIONAL REQUIREMENT}

The system must protect itself from infection by unauthorised programs (e.g. virus, worms, trojans).

1.1 It must carry out period virus checks of the systems and data.

1.2 It must update its virus and malware definitions on a regular basis as specified by policy.

1.3 It must notify the system administrator of any compromised systems or files.

1.4 It must generate a virus scan report and make it available to the system administrator.

\section{REQ-67 COOKIE ALERT}

\section{LEGAL REQUIREMENT}

The system (the repository \& the public website) shall alert users to the use of non-essential cookies with respect to current legislation e.g. EU directive.

1.1 It must allow users to opt-in or opt-out to using cookies.

1.2 It must provide users with access to a privacy notice.

\section{REQ-68 MAPPING INTERFACE}

\section{INTERFACE REQUIREMENT}

The system must provide a mapping interface with markers.

\section{REQ-69 TIME-CODING}

\section{FUNCTIONAL REQUIREMENT}

The system must allow the user, in accordance with their access rights, to save a segment of an audio or moving image file to their workspace.

\section{REQ-70 TIMELINE INTERFACE}

\section{INTERFACE REQUIREMENT}

The system must provide a timeline interface with date segments (start-end dates) as per the data model of the timeline tool.

\section{REQ-71 INDEX TEXT}

\section{FunctionAL REQUIREMENT}

The system must scan document files, in accordance with the access rights of that object, to build an 
index of search terms.

1.1 It must update the index after a document has been replaced or access rights changed.

\section{REFERENCES}

Cassidy, K., Collins, S., Covone, F. V., Frost, D., Gallagher, D., Kenny, S., Kilfeather, E., Martínez-García, A., McGoohan, C., O'Neill, J., Redmond, S., Tang, J., Tiernan, P. and Webb, S. (2015) Building the Digital Repository of Ireland Infrastructure (R. Grant, J. O'Neill and S. Webb, Eds.). Maynooth: Maynooth University; Dublin: Trinity College Dublin; Dublin: Royal Irish Academy; Galway: National University of Ireland, Galway. DOI: http://dx.doi.org/10.3318/DRI.2015.5

O'Carroll, A. and Webb, S. (2012), Digital archiving in Ireland: national survey of the humanities and social sciences. National University of Ireland Maynooth. 